\title{
Bases iniciales para el mejoramiento del servicio de transporte público en una ciudad venezolana
}

\author{
José Guillermo García Chourio*
}

\begin{abstract}
This paper presents the conceptual, legal and strategic foundations that have to be taken into account to improve the urban transport system in one of the most important cities in Venezuela. Following the Logic Frame Approach methodology, we carried out an empirical approximation to the poor provision of this service in Maracaibo City. This was analysed considering the theoretical nature of this activity as a local public service at a time in which descentralisation offers a structure of political opportunity for the development of a social economy in this sector. This is done through the creation of a network of transport cooperatives that not only contribute to the improvement of the service, but also to the generation of social capital.
\end{abstract}

Keywords: local public services, public policy, urban transport, descentralisation, municipality, Venezuela.

\section{Resumen}

En este trabajo se plantean los fundamentos básicos de orden conceptual, legal y estratégico que deben ser considerados para el mejoramiento del servicio de transporte urbano en una de las principales ciudades de Venezuela. Siguiendo la metodología del Enfoque Marco Lógico se realizó una aproximación empírica en torno a la deficiente prestación de ese servicio en la ciudad de Maracaibo, la cual fue analizada considerando la naturaleza teórica de dicha actividad como un servicio público local en momentos en que la descentralización ofrece una estructura de oportunidad política para el desarrollo de una economía social en dicho sector, mediante la creación de una red de cooperativas de transporte que además de contribuir a mejorar el servicio, posibilite la generación de capital social.

Palabras clave: servicios públicos locales, política pública, transporte urbano, descentralización, municipio, Venezuela.

* Universidad Católica Cecilio Acosta y Universidad del Zulia, Venezuela. Correoe: jggarcia@unica.edu.ve. 


\section{Introducción $^{1}$}

En el marco de la descentralización político-administrativa que ha vivido Venezuela en los últimos años, la agenda de políticas públicas de los gobiernos subnacionales se ha visto reconfigurada a partir del fortalecimiento de las competencias que éstos han ganado. Ello ha puesto sobre el tapete la cuestión del mejoramiento en la prestación de los llamados Servicios Públicos Locales (SPL), en momentos en que el ciudadano ha despertado de su rol pasivo de usuario-contribuyente, para convertirse cada día más en un cliente exigente de un servicio de calidad.

La gestión directa de la política del transporte urbano ha sido una de las tareas que han asumido los gobiernos municipales a fin de lograr una mejor prestación de ese servicio. Así, las alcaldías han adquirido un papel importante en el diseño de su propia política, que ha ido desde la creación de sistemas integrados de transporte urbano hasta la planificación y ejecución de proyectos de Metro.

En el caso del municipio Maracaibo, ${ }^{2}$ una política integral dirigida a solventar el problema del servicio de transporte colectivo la constituyó la Red Maestra de Transporte, la cual surgió en el marco de la política de municipalización del transporte urbano que ha adelantado desde inicios de la década de 1990 el Ministerio de Transporte y Comunicaciones por medio del Fondo Nacional de Transporte Urbano (Fontur). Dicha política ha estado dirigida a aquellos municipios con una población mayor de 100,000 habitantes, estimándose que por la densidad poblacional pudiese existir un mayor déficit de unidades de transporte.

En este trabajo se tiene como objetivo, tras realizarse una aproximación empírica sobre el creciente deterioro de la Red Maestra de Transporte Público Urbano de la ciudad de Maracaibo, desarrollar las bases iniciales para una propuesta de intervención que contribuya al mejoramiento del servicio de transporte público urbano en dicha ciudad. Se parte de considerar

${ }^{1}$ El autor agradece el apoyo del Fondo Nacional de Ciencia, Tecnología e Innovación de Venezuela (Fonacit) para el desarrollo de esta investigación en el marco del Programa de Formación de Talento. Núm. de Subvención: 2001000295.

${ }_{2}^{2}$ Este municipio abarca territorialmente la mayor extensión $\left(393 \mathrm{~km}^{2}\right)$ de la zona metropolitana de la ciudad de Maracaibo, segunda ciudad en importancia del país por su tamaño poblacional (más de un millón doscientos mil habitantes, según cifras del Instituto Nacional de Estadística [INE], 2005) y nivel de actividad económica. Dicha ciudad viene a ser la capital del estado de Zulia, principal estado productor de petróleo, situado en el extremo norte occidental de Venezuela. 
que el proceso de descentralización ha posibilitado el desarrollo de una estructura de oportunidad política en la que la dirección seguida por cualquier política pública local se ve ahora expuesta a presiones de una serie de actores sociales y políticos que antes no tenían cabida, cuando los procesos subnacionales de toma de decisiones eran manejados casi en su totalidad por el gobierno central.

En la primera parte del trabajo se analiza, a partir de una visión crítica sobre la teoría de la Nueva Gerencia Pública (NGP) (Dunleavy y Hood, 1995; Barzelay, 1998), el contexto institucional en el que surge la política de municipalización del transporte público en Venezuela como política de transferencia de competencias, que abre espacio -en el marco de la descentralización- a una serie de actores más allá de los pertenecientes a la esfera estatal. En la segunda parte se presenta una descripción de la problemática que atraviesa hoy en día la Red Maestra, mediante el desarrollo de un árbol del problema en el que se ofrece una panorámica de las causas que han originado la deficiente prestación del servicio de transporte, así como de las consecuencias que está teniendo para el municipio.

En tercer lugar se pasa a considerar los orígenes de dicho servicio de transporte y su evolución a lo largo del tiempo, a partir de un breve esbozo de la gestión desarrollada por las autoridades municipales. En un cuarto momento se sitúan las bases legales que imponen obligaciones jurídicas a las alcaldías en cuanto a su responsabilidad de resolver el problema y gestionar el mejoramiento y calidad del servicio del transporte. Para esa misión de los gobiernos municipales, en el quinto apartado del trabajo se considera fundamental el desarrollo de una propuesta de intervención que se apoye en una alternativa teórica distinta al paradigma de la Nueva Gerencia Pública, como es el caso de la teoría Neoinstitucional (Putnam, 1993; North, 1993), la cual permite reconocer la potencialidad de asociacionismo como modelo de gestión idóneo para la administración de un servicio público local, como es en este caso el transporte urbano, el cual necesariamente pasa por su tercerización a Organizaciones no Gubernamentales (ONG) y cooperativas, organizaciones que por su enorme organicidad pueden apuntalar el desarrollo de un capital social que impulse un fortalecimiento de la asociatividad en torno a la Red Maestra de Transporte. 


\section{Nueva Gerencia Pública y municipalización del transporte}

En el marco de la descentralización político-administrativa que ha vivido el país en los últimos años, uno de los problemas que se ha hecho presente en la agenda de políticas públicas de los gobiernos subnacionales es el relacionado con el mejoramiento en la prestación del servicio de transporte urbano de pasajeros. Es así como mediante la transferencia de competencias, propia del proceso de reforma del Estado, adquieren relevancia cuatro ideas-fuerza propias del paradigma de la NGP: autonomía de los servicios, competencia entre ellos, contractualización de sus relaciones, y control de los consumidores o "clientes" (Cunill, 1999: 102).

En el caso del municipio de Maracaibo, el inicio de una política integral dirigida a solventar el problema del déficit de unidades de transporte colectivo surgió con base en dichas ideas-fuerza a comienzos de la década de $1990 .{ }^{3}$ Dicha política, emanada en cuanto a sus directrices principales del nivel central, ha estado orientada hacia la promoción de un formato flexible que posibilite el logro de óptimos niveles de eficiencia de acuerdo con un nuevo diseño institucional del Estado que concibe a los gobiernos locales como entes autónomos para la decisión y ejecución de actividades y prestación de servicios públicos.

La supuesta libertad individual de los agentes sociales, políticos y económicos dentro del eje global-local implica "depender de unidades autónomas cuyos líderes posean mucha mayor discrecionalidad y puedan ser juzgados por sus resultados" (Crozier, 1997: 13). Significa otra forma distinta de organización de los gobiernos, donde el diseño más avalado por la circunstancias económicas actuales "nos remite automáticamente al presupuesto por objetivos, a los indicadores de resultados, a la separación de los roles, o a la imagen de una red compleja de contratos" (Dunleavy y Hood, 1995: 107).

En medio de ese espacio de autonomía, la transformación de las relaciones de propiedad estatal en propiedad privada mediante el traspaso de funciones y servicios del Estado hacia otros sectores de la sociedad, es otra de las características del nuevo diseño

${ }^{3}$ En armonía con los cambios hacia una economía de mercado, emprendidos a partir de 1989 durante la segunda presidencia de Carlos Andrés Pérez, las alcaldías de las principales ciudades del país llevaron a cabo, en coordinación con el Ministerio de Transporte y Comunicaciones, una política de municipalización del transporte urbano de corte neoliberal que implicó un aumento de las tarifas del transporte público a raíz de la incorporación de operadoras privadas en la prestación del servicio. 
administrativo, o mejor dicho "gerencial", del aparato público, que aboga por la búsqueda de la eficiencia y la productividad. En el caso de la política de municipalización del transporte urbano, los usuarios pasan ahora a considerarse como clientes, donde más a allá de ser revestidos con este sugerente calificativo debido a que es con base en sus preferencias que se configura la oferta de bienes y servicios, el mismo obedece a que el ciudadano es forzado a un espacio de consumo regido por un sistema de precios en lo referente a unos bienes que secularmente se han calificado como insustituibles.

A partir del Programa Nacional de Transporte Urbano, que se desarrolló con recursos provenientes de la banca multilateral desde inicios de 1990, se han introducido criterios de eficiencia y rentabilidad en la administración de los sistemas de transporte, con el otorgamiento de contratos de servicio a operadoras privadas, la eliminación de los subsidios sobre las tarifas, y la aplicación de la figura de Fondos ${ }^{4}$ como mecanismo de acceso al financiamiento para la generación de políticas por parte de los entes municipales. Este principio rector de la administración de los recursos financieros con base en fondos sociales, a los cuales tendrían acceso los gobiernos locales mediante la presentación de proyectos, ha respondido a un componente de reforma institucional que ha tenido que ver con el proceso de creación o fortalecimiento de agencias encargadas de regular la política municipal de transporte.

Paralelo a la disminución de las actividades estatales como consecuencia de la privatización, se requiere construir una capacidad normativa y reguladora que permita a los gobiernos locales coadyuvar en el desarrollo de la estructura productiva de los municipios. Flexibilizar la producción y abrir canales regulados para la competencia en la prestación de servicios se constituye en uno de los nuevos roles que le toca cumplir al Estado, con miras a promover mercados que generen una óptima asignación de los recursos. Por un lado, se debilita el Estado como ente proveedor de servicios y, por el otro, se fortalece su actividad reguladora sobre actores pri-

\footnotetext{
${ }^{4}$ En 1990 se creó el Fondo Nacional de Transporte Urbano (Fontur), que surgió como respuesta a la necesidad de una instancia organizativa flexible y expedita que permitiera al Gobierno, por medio del Ministerio de Transporte y Comunicaciones, coordinar y canalizar los recursos financieros para programas y proyectos de transporte urbano hacia las instituciones locales en el marco del Programa Maestro de Transporte Urbano.
} 
vados dentro de un ámbito territorial, ${ }^{5}$ el cual ha sido reconocido como propicio para la generación de productos que se busca comercializar internacionalmente (Borja, 2002).

La creación del Fontur obedeció a un cambio en la concepción sobre el financiamiento y la fuente de los recursos de las políticas de transporte público urbano en Venezuela. En este aspecto, el nuevo paradigma de la política deja de lado la concepción de que el Estado debe asumir el financiamiento total de los programas de transporte e introduce las modalidades de cofinanciación con actores privados o del tercer sector y de autogestión de la comunidad en los proyectos. Con base en este nuevo modelo de gestión, la privatización y tercerización de las actividades y servicios del aparato estatal descentralizado permitirían el desarrollo de mercados o cuasimercados de servicios públicos locales, donde empresas y ONGs establecen con las autoridades públicas una red de contratos para la prestación, los cuales adoptan las más diversas modalidades.

El patrón de articulación Estado-sociedad en el ámbito de los gobiernos municipales, si bien considera trasformaciones en el plano político y una reestructuración intra burocrática del propio aparato público, está en gran medida orientado con base en la llamada descentralización económica, que en su objetivo de hacer más eficiente la asignación de los recursos y la producción de bienes y servicios locales, ha puesto sobre el tapete la cuestión de cuáles son las tareas y actividades que pueden ser transferidas al sector empresarial.

Por mucho que la descentralización económica prevista en la política de municipalización del transporte pretenda contribuir a sacar del universo de las restricciones burocráticas a la producción y provisión de un servicio público que se ha caracterizado tradicionalmente por ser deficiente, la coordinación por parte de las autoridades municipales en torno a dichos procesos es fundamental, debido a que la lógica inclusiva que debe poseer dicha prestación da cuenta de una política pública sectorial que

${ }^{5}$ La especialización de cada uno de los niveles del Estado mediante la descentralización, se ha realizado con el argumento de mejorar la relación costo-efectividad de las políticas, a partir de considerar que la autonomía y la proximidad de los gobiernos locales le agregan a este nivel "otras ventajas 'comparativas' como son la integración de políticas públicas, su adecuación a demandas heterogéneas, la cooperación y el control social, su adaptación flexible al cambio, etc.” (Borja, 2002: 57). De manera que el reemplazo del tradicional modelo jerárquico vertical centralizado por un esquema de autonomía federativa, independientemente de su potencial democratizador, está relacionado con fines más de naturaleza económica que política. 
está sujeta a interdependencias que no siempre pueden ser obviadas. Sustituir la actuación estatal por la de la iniciativa privada en la esfera de ese servicio público no conduce directamente a una asignación eficiente de los recursos. Privatizar las relaciones entre el proveedor y el receptor del servicio público de transporte no debe limitarse al mero traspaso de la titularidad pública a la privada mediante la venta de activos u otorgamiento de contratos. "La experiencia mercantil tiene que ser filtrada de forma adecuada, ya que ni el mercado ni la competencia pueden funcionar en ausencia de un marco institucional (Gomà y Brugué, 1994: 219).

En este sentido, si bien es necesario reconocer que la grave crisis fiscal ha obligado a asumir criterios de recuperación de costos en la esfera de la administración de los servicios de transportes, hasta ahora el traspaso de dicho servicio a concesionarios privados no ha significado una mejora sustancial en su prestación. Más bien, la experiencia en Venezuela ha venido demostrando cómo en un sector con escasos sistemas de regulación y control estatal, al fallar los mecanismos de mercado, la prestación del servicio decae en cuanto a su calidad, perdiendo sostenibilidad cualquier política de mejora del mismo, como ha sido el caso de la Red Maestra de Transporte en la ciudad de Maracaibo.

\section{Una mirada objetiva en torno al problema}

En los últimos años se ha venido observando cómo el sistema de transporte colectivo urbano creado por la municipalidad, denominado Red Maestra de Transporte, ha desmejorado profundamente su servicio al pasajero. Un árbol del problema (figura I) nos permite evidenciar, entre los indicadores de dicha situación, la demora exagerada que sufre el pasajero a la espera de las unidades de transporte, las cuales tardan una media aproximada de 25 minutos en frecuencia de llegada entre una parada y otra. ${ }^{6}$ Esto significa que una persona que opte por ese servicio puede perder aproximadamente una hora/hombre en un recorrido de 10 kilómetros, lo cual también puede variar hacia a la baja o, peor aún, incrementarse debido a que no existe un horario establecido de llegada en ninguna de las paradas de las 11 rutas que conforman la Red.

${ }^{6} \mathrm{El}$ intervalo proyectado en el diseño era de siete minutos; sin embargo, debido a que la flota estaba por debajo de lo requerido, era lógico esperar que se elevara la demora en la frecuencia. 


\section{Figura I \\ Árbol del Problema}

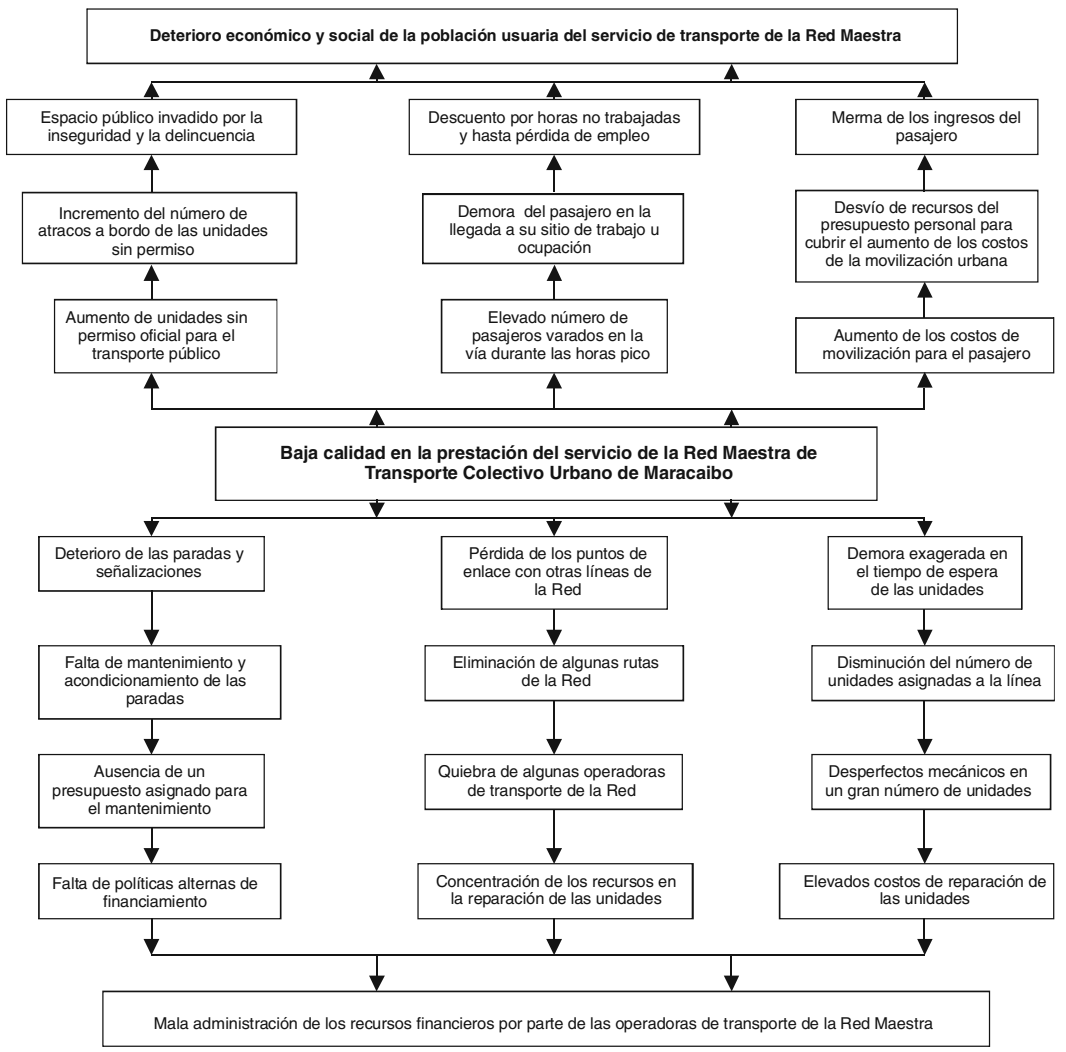

Fuente: Elaboración propia.

La situación de demora de las unidades ya era algo latente en el propio diseño de la Red. La mayoría de las rutas tienen un trayecto de entre 13 y 31 kilómetros que recorren prácticamente la zona metropolitana de la ciudad mediante un sistema de paradas con una distancia de separación de unos 500 metros entre una y otra, lo cual implicó para las 86 unidades de transporte (entre ocho y siete unidades por cada ruta) existentes en un principio, una probabilidad de hacer un alto en más de la mitad de las entre 26 y 62 paradas que podía tener una determinada ruta, y 
donde la velocidad máxima permitida al autobús es de $70 \mathrm{~km} / \mathrm{h}^{7}$ En esas circunstancias, los tiempos de espera de la unidad por parte del pasajero se hacían notablemente más largos en comparación con los del tradicional servicio de autobuses prestado por las asociaciones de propietarios y conductores de transporte público, que se desarrolló de manera reactiva frente a las demandas surgidas en la ciudad, dadas las condiciones de crecimiento y expansión urbana (Figueroa, 2004). ${ }^{8}$

La baja competitividad con la que se estableció el servicio en cuanto a rapidez y precio ${ }^{9}$ sólo se vio compensada durante un tiempo por lo atractivo que significó para el usuario la puesta en circulación de unidades nuevas y de última generación importadas de Brasil, las cuales por su comodidad y espacio interior se distanciaban enormemente, en términos de calidad, del tradicional servicio de transporte urbano, caracterizado por un parque automotor con más de 30 años de antigüedad, en desperfecto creciente de sus unidades y con altos niveles de contaminación, lo que se combina con una imagen deplorable del personal y una atención al usuario sin las más mínimas normas de respeto y garantía de su seguridad durante el viaje.

Otra novedad del servicio prestado por las empresas operadoras de la Red, por insólito que parezca, fue el uso de paradas reglamentarias para el embarque y desembarque de pasajeros, lo

${ }^{7}$ El interés del gobierno municipal de ese entonces, de establecer una red mediante enlaces entre las rutas en algún punto de su recorrido dentro de una zona con una extensión de más de $300 \mathrm{~km}^{2}$, y no mediante un sistema de intercambiadores que sirvieran como estaciones intermedias de conexión de rutas más cortas, limitó desde un principio la rapidez en la prestación del servicio de las empresas a las que les fueron adjudicadas las concesiones de operación.

${ }^{8}$ Más allá de la funcionalidad dinámica entre el desarrollo de la infraestructura de servicios públicos y la expansión urbana que plantea Figueroa, y que en países como Argentina y Chile estuvo regulada por el Estado durante el modelo de sustitución de importaciones, hay que señalar que en el caso del transporte público en Venezuela, y particularmente en Maracaibo, su surgimiento y desarrollo reactivo han sido escasamente regulados por las autoridades estatales.

${ }^{9}$ La tarifa del servicio de la Red Maestra ha sido desde el principio 20\% superior a la del resto del transporte público urbano operado por las tradicionales asociaciones de propietarios y conductores. A esto también hay que agregar que el estado de Zulia, y principalmente Maracaibo, ha sido desde los inicios de la explotación petrolera a comienzos del siglo xx, la zona del país donde el servicio de transporte urbano nació y se consolidó como el más costoso, sin que haya una mayor diferencia con el que se presta en otras ciudades venezolanas. Un factor explicativo de esa situación fue durante mucho tiempo el impacto que la actividad petrolera tuvo en el ingreso promedio de las familias marabinas, las cuales por décadas fueron sujetas a una gran movilización social que dio paso al uso del automóvil particular, con lo cual se estancó la demanda del servicio de transporte público y la oferta del mismo decreció, muy a pesar de que la ciudad seguía creciendo poblacional y territorialmente hacia la periferia. 
que dio una imagen "moderna" a un servicio que tradicionalmente no ha utilizado de manera obligatoria el sistema de paradas dentro de las rutas en que operan las diferentes líneas de transporte urbano en Maracaibo. ${ }^{10}$ En este sentido, el establecimiento de la Red implicó la colocación de decenas de paradas techadas y tipo "tótem" las cuales en la actualidad expresan un grave deterioro de su infraestructura debido a la falta de mantenimiento, pues en el contrato de servicio no quedó claro si correspondería a la municipalidad o a la empresa prestataria esa tarea de mantenimiento. Ejemplo elocuente de esta situación es que las paradas "tótem" fueron invadidas por una corrosión que en muchos casos significó su caída, y en otros, por su estado de abandono, fueron robadas por personas dedicadas al contrabando de chatarra metálica como estrategia de sobrevivencia.

$\mathrm{Al}$ deterioro de las señalizaciones, lo que dificulta al usuario determinar las paradas reglamentarias, se une la pérdida de enlace de los puntos que en principio conformaban y le daban organicidad a la Red. La eliminación de la mayoría de las rutas que tenía la Red ha sido un fenómeno progresivo y hasta cierto punto se puede pensar que ha sido deliberado. El punto de partida de esa situación fue la mengua en el número de unidades asignadas a algunas líneas como resultado de los enormes desperfectos mecánicos de muchos autobuses a falta de un mantenimiento preventivo. Esa circunstancia ha afectado al usuario, en vista de que se ha incrementado aún más el tiempo de espera, ya que las unidades restantes no logran generar el efecto de pasar constantemente por las paradas. El excesivo tiempo de espera ha significado que el usuario vea poco atractivo en el servicio, a pesar de que el mismo sea necesario, con lo cual cada vez es menor el número de pasajeros que esperan las unidades de la Red.

El abandono del servicio por parte del usuario es una circunstancia que ha sido utilizada por las propias operadoras para justificar ante la municipalidad la eliminación de la ruta y la finalización del contrato, ocultándose que el verdadero motivo es el

${ }^{10}$ En el municipio hay casi medio centenar de asociaciones cooperativas y gremiales que agrupan a propietarios y conductores de transporte público masivo de pasajeros, que comprende líneas de autobuses y carros por puestos, siendo estos últimos los de mayor fuerza política como grupo de interés ante las autoridades municipales de transporte. Las últimas huelgas de sólo ocho horas en ese sector del transporte público urbano por demandas como el aumento de las tarifas y/o mayor nivel de resguardo policial frente a la inseguridad en la prestación del servicio, han significado el retraso o la paralización total de muchas de las principales actividades del municipio, dada la imposibilidad de grandes contingentes de personas de trasladarse a su sitio de trabajo o estudio. 
estado de ruina en que han caído las mismas operadoras por la mala administración del servicio, así como la situación de grandes desperfectos de las unidades y de los altos costos que representa reparar ahora unas máquinas a las que no se les ha dado mantenimiento, ante lo cual se ha preferido cerrar actividades, liquidando a un contingente de choferes sujetos a un precario contrato laboral que no superaba los dos salarios mínimos mensuales, o sea, unos 500 dólares americanos.

La falta de mantenimiento a los autobuses significó para algunas operadoras, ya en última instancia, concentrar sus recursos financieros en la costosa pero ineludible tarea de reparar las unidades. Ese costo no pudo ser asumido durante mucho tiempo por algunas de las empresas, en vista de que la mayoría de los repuestos y accesorios tenían que ser importados de la unidad productora Mercedes-Benz en Brasil. Frente a la disminución de las ganancias netas a raíz de la inyección de recursos para las reparaciones de los autobuses, y ante la cuantiosa inversión que implicaría actualizar la flota de unidades, algunas empresas prefirieron cerrar operaciones, mientras que otras redujeron el número de autobuses en circulación y lograron eliminar una gran cantidad de rutas, resultado que fue bien recibido por algunas cooperativas de transporte de autobuses y carros por puestos de pasajeros de esas rutas, quienes habían visto mermada su clientela a partir de la entrada de las operadoras de la Red. ${ }^{11}$

El escaso compromiso de las autoridades locales en el desarrollo de una política de subsidio para ese proyecto, el cual de por sí necesita el apoyo de fuentes alternas de financiamiento, por lo menos para el mantenimiento de la infraestructura física de las paradas y las señalizaciones, dejó en manos de las operadoras privadas la gestión casi exclusiva del servicio, el cual fue asumido por esas empresas como un negocio más, lo que hizo de un servicio básico e importante para la ciudad, una actividad netamente mercantil que no toma en consideración el carácter "público". Al contrario de lo que postula la NGP, la privatización, en este caso, no ha dado al usuario un abanico de opciones para elegir. Más bien, la forma como se ha gestionado el servicio pri-

${ }^{11}$ La fijación de una tarifa más elevada en el caso de la Red como parte del proceso de privatización del servicio fue aprovechada por las demás asociaciones de transporte, que presionaron a la municipalidad para una homologación de todas las tarifas con base en el precio fijado para esas operadoras, lo que resultó al final en la creación de una especie de oligopolio del transporte que ha confinado al usuario a pagar el mismo precio en cualquiera de los servicios de transporte que se ofrecen independientemente de la calidad del servicio. 
vatizado ha ido en desmedro de la atención y el servicio al pasajero, el cual se ha visto ahora en la obligatoria necesidad de optar por otros tipos de servicios de transporte más onerosos como los taxis, o muy inseguros como son las unidades sin permiso oficial, conocidas como "piratas", que congestionan aún más el tráfico automotor, elevando el número de robos y colisiones en las horas pico.

La progresiva eliminación de rutas como La Victoria (Trayecto Centro-Noreste), Cuatricentenario (Trayecto Centro-Suroeste) y Sabaneta (Trayecto Centro-Sureste) ha propiciado que en las horas punta muchos habitantes de esos sectores de la ciudad se queden varados en las vías y en largas colas de las paradas de carros por puestos. Esa demanda del servicio ha sido asumida por los taxis y los piratas, lo que ha representado para el usuario un aumento en los costos de movilización -de hasta seis veces su importe base- si en una situación de premura utiliza el servicio de taxis, o bien un riesgo de ser objeto de robos si utiliza un pirata, debido a que ese tipo de transporte es propicio para la ejecución de actos delictivos y hasta lesivos a la integridad física del pasajero. ${ }^{12}$

Aquellos usuarios que optan por el servicio de taxis para dirigirse a su sitio de trabajo, ven mermados sus ingresos mensuales debido al desvío de recursos destinados a otras necesidades básicas, y que ahora deben ser utilizados en el sobrepago no presupuestado que acarrea la utilización imprevista de ese servicio. ${ }^{13}$ Otros usuarios que se dilatan en espera de un transporte más económico para trasladarse a sus ocupaciones, corren el riesgo de demora e impuntualidad en sus responsabilidades laborales, lo cual puede generar desde amonestaciones por parte de los superiores, pasando por descuentos por horas no trabajadas, hasta la posible pérdida del empleo.

${ }^{12}$ La operación creciente de unidades de transporte público sin licencia para operar se ha convertido en una estrategia de sobrevivencia de una franja de la población económicamente activa que se encuentra en un estado de desempleo estructural, y que constituye 17\% (INE, 2005). Los trabajadores de ese sector informal de la economía son personas que reconvierten el vehículo familiar en una unidad de transporte de pasajeros, que o bien operan sus propios dueños o que se cede en alquiler a un tercero para que éste realice dicha actividad.

${ }^{13}$ El servicio de transporte público colectivo en Maracaibo es usado en gran medida por el asalariado bajo y el trabajador de la economía informal. El primero, que utiliza el servicio de forma diaria durante los días laborables, percibe entre uno y dos salarios mínimos, unos 500 dólares americanos, de lo cual destina aproximadamente 20\% mensual al pago de ese servicio. En el caso del segundo es más difícil determinar la frecuencia de uso del servicio y el nivel de ingreso, ya que ambos son muy variables, pero se puede hablar de una media de uso de 4.3 veces a la semana y de un ingreso por encima de un salario mínimo. 
El fomento de una gran flota de transporte público sin permiso oficial -lo cual trae aparejado un incremento de la inseguridad pública- y la merma en los ingresos de un usuario obligado a pagar por un servicio más costoso se combinan, añadiendo un elemento más de peso en el sofocante cuadro de deterioro económico y social del propio ciudadano, quien para escapar y/o hacerle frente a ese deterioro, se encuentra atrapado ahora en otro de los tantos dilemas urbanos de las metrópolis venezolanas: cancelar altas tarifas por un transporte que debería ser económico, rápido, seguro y de calidad, o verse expuesto a perder su empleo o ser impuntual e irresponsable ante las tareas y ocupaciones que debe realizar fuera de su domicilio.

La mala administración de los recursos financieros por parte de las operadoras de la Red Maestra y la escasa regulación y control por parte de las autoridades municipales sobre las actividades que en la rama del transporte público han sido cedidas en concesión a empresas privadas, son al final de cuentas los principales factores explicativos del deterioro de la principal política pública de transporte que se ha llevado a cabo en la ciudad de Maracaibo a partir del proceso de descentralización iniciado a finales de 1980. Desde un principio, la poca transparencia en los contratos de adjudicación, así como la escasa apertura y convocatoria hacia los propios usuarios como partícipes en la vigilancia y control de dicho servicio, han puesto en evidencia un afán privatizador con alta prescindencia social que daba por sentada una mejora significativa del servicio en una lógica exclusivamente mercantil del mercado.

\section{Origen y evolución del servicio de la Red Maestra de Transporte}

La Red Maestra de Transporte Público de Maracaibo fue un proyecto que nació al amparo del convenio firmado en 1992 entre el Fontur y el Instituto Municipal de Transporte Colectivo Urbano de Pasajeros de Maracaibo (Imtcuma). Dicho convenio, denominado Asignación y Permiso de Operación de Rutas de Transporte Urbano de Personas para la Ciudad de Maracaibo, se enmarcó en lo que fue la política de municipalización del transporte urbano en la ciudad durante la gestión del alcalde Fernando Chumaceiro, de orientación socialcristiana, y cuyo objetivo fundamental era establecer un programa de inversión conjunta para la adquisición de unidades de transporte colectivo, con el propósi- 
to de modernizar el transporte público, como área crítica de la ciudad de Maracaibo.

Con créditos de la Banca Multilateral, el financiamiento general que se desprende del convenio con Fontur implicó la concesión a un grupo de empresas privadas para la adquisición y operación de 86 unidades. Las empresas beneficiadas en ese acuerdo inicial fueron Transporte Consolidado, CA; Transporte Urbano de Maracaibo, CA (Transumarca), y Colectivos Corazón de Jesús, CA. Dichas empresas, de capital nacional, fueron creadas meses antes de los concursos de licitación por un grupo de empresarios zulianos, básicamente al calor del inminente proceso de privatización, por lo que no tenían la más mínima experiencia en la gestión de servicios de transporte público urbano.

Las rutas iniciales fueron: 18 de Octubre, San Jacinto (Trayecto Centro-Norte), Sabaneta, Cuatricentenario, El Silencio (Trayecto Centro-Suroeste) y La Victoria (Trayecto Centro-Noreste), servicio operado por Transportes Consolidados; la ruta del sector La Limpia (Trayecto Centro-Noroeste), operada por Colectivos Corazón de Jesús, y la ruta de Haticos-El Bajo (Trayecto CentroSur), operada por Transumarca. Pero el surgimiento de la red orgánica de transporte no ocurrió sino hasta la segunda gestión del alcalde Manuel Rosales (1997-2000), en concordancia con el proyecto de los Corredores Viales construidos o mejorados para facilitar la prestación del servicio; surgieron entonces las siguientes rutas: Delicias (Línea A, azul: Trayecto Norte-Sur), Curva del Molina (Línea B, amarilla: Trayecto Centro-Oeste), Circunvalación 2 (Línea D, verde: Trayecto Norte-Suroeste), y se amplió la anterior ruta de Sabaneta (Línea C, roja).

Desde un principio, las autoridades municipales vieron la deficiente prestación del servicio de transporte colectivo urbano como una situación de déficit de unidades, de allí que uno de los objetivos principales del convenio fuera precisamente la adquisición de unidades de autobuses para el municipio. A partir de ese momento, la Alcaldía le asignó la explotación de nuevas rutas (en los sectores más críticos) principalmente a la empresa Transporte Consolidado, CA, y de esa forma se incorporaron más de 71 nuevas unidades de transporte colectivo. En ese momento se inauguró un proceso de reglamentación de un servicio que por décadas había estado exclusivamente en manos de las asociaciones de propietarios y conductores del transporte, a los cuales la municipalidad y las autoridades de tránsito terrestre sólo registraban y matriculaban como operadores de determinadas rutas 
que surgían de forma reactiva ante la crecimiento de la ciudad, negociando con esos gremios cada cierto tiempo los aumentos de las tarifas como resultado del alza en los precios de los combustibles que decretaba el Ejecutivo Nacional.

A diferencia de otras urbes latinoamericanas como Buenos Aires, Santiago y Sau Paulo, las ciudades venezolanas, y en este caso Maracaibo, se han caracterizado por una escasa reglamentación del servicio de transporte público. Es más bien a partir de los procesos de privatización impulsados por el ajuste neoliberal, que se ha intentado regular un servicio que se supone ahora debe ser liberalizado. La baja capacidad institucional de muchas alcaldías venezolanas surgidas en los momentos en que se daban los procesos de privatización de los servicios es un factor que debe ser considerado a la hora de explicar los desastrosos resultados que han tenido los servicios traspasados al sector privado, como en este caso ha sido la experiencia de la Red Maestra de Transporte Público.

El contexto institucional en el cual evolucionó la Red Maestra estuvo caracterizado por un juego entre los actores en cuestión (Banca Multilateral a través del Fontur, autoridades municipales, operadoras privadas y asociaciones y gremios de transporte público), donde se combinaba el expediente de la privatización del servicio como racionalidad técnica para procurar la eficiencia, con una gestión pública clientelar basada en el tráfico de influencia y el intercambio particularizado. Un ejemplo de ello fue la política de ampliación de la Red, que consistió en el desarrollo de una Red Complementaria de Transporte cuyo objetivo era el fortalecimiento de algunas rutas ya existentes en la ciudad, con el financiamiento de nuevas unidades de transporte. Dicho proyecto se llevó a cabo mediante el otorgamiento de créditos a tasas muy bajas que fueron repartidos de forma directa a personas vinculadas con la red político-partidista y gremial que servía de plataforma a la gestión del alcalde de ese entonces, y donde jugó un papel fundamental la presión de las Cooperativas de Transporte ya existentes, que habían visto invadido su espacio de operación en muchas de sus rutas desde la entrada en circulación de las empresas de la Red Maestra Central.

Con el paso del tiempo, muchas de esas rutas iniciales ya han desaparecido; es el caso de Sabaneta, San Jacinto, La Victoria, El Silencio y Cuatricentenario. La falta de mantenimiento de las unidades en las rutas restantes hace inminente en el mediano plazo su salida de circulación, con lo cual terminará por desaparecer el sis- 
tema de Red Maestra. Todo este descalabro no viene sino a poner en tela de juicio que la transferencia al sector privado de dicho servicio público contribuya a mejorar su prestación, y menos aún en condiciones de ausencia de control y regulación por parte de los gobiernos municipales. No haber considerado otras alternativas como la promoción de cooperativas de transporte para el manejo del servicio, no hizo más que evidenciar el empeño de las autoridades locales de turno en privilegiar un proceso de privatización a ultranza, en beneficio de cierto sector del empresariado local que vio en este proyecto una oportunidad de negocio.

\section{Bases jurídicas que exigen la atención del servicio por parte del municipio}

En la Constitución Nacional, el municipio como unidad administrativa asume una importancia política que nunca había tenido en nuestra historia republicana. Expresamente en el Título IV, Capítulo Iv, Artículo 168, se define al municipio como la unidad política primaria de la organización nacional dentro los límites de la Constitución; y su autonomía comprende la elección de sus autoridades, la gestión en materias de su competencia y la creación, recaudación e inversión de sus ingresos (Asamblea Constituyente, 1999).

Asimismo, en el siguiente aparte del mismo Artículo se establece que las actuaciones del municipio en el ámbito de sus competencias se cumplirán incorporando la participación ciudadana en el proceso de definición y ejecución de la gestión pública y en el control y la evaluación de sus resultados, en forma efectiva, suficiente y oportuna, conforme a la ley. Esto constituye un avance significativo e innovador en materia del ejercicio de las competencias municipales, pues se le da a la participación ciudadana una posibilidad con rango constitucional para intervenir en la definición, ejecución, control y evaluación, dentro de la gestión de las competencias municipales.

En el Artículo 178 se establecen las atribuciones del municipio, al que le corresponde el gobierno y administración de sus intereses y de las materias que le asigne la Constitución y las leyes nacionales, con todo lo relacionado con la vida local, en especial con la ordenación y promoción del desarrollo económico y social, la dotación y prestación de servicios públicos domiciliarios y, entre otras competencias, el mejoramiento general de las condiciones de vida de la comunidad. En ese sentido, espe- 
cialmente en materia de transporte público se indica en numeral 2 del Artículo, que en la competencia de vialidad urbana es potestad del municipio la circulación y ordenación del tránsito de vehículos y personas en las vías municipales, así como el servicio público de transporte urbano de pasajeros.

Así, la actual Constitución de 1999 asigna la prestación del servicio público de transporte urbano a los municipios, como parte de sus competencias; sin embargo, se reserva para el Poder Nacional el régimen de transporte público urbano de pasajeros realizado a través de vías férreas (Art. 156, ordinal 27).

En el caso de la Ley Orgánica de Régimen Municipal (LORM) de 1989, se establece en su Artículo 1 que su objeto es el desarrollo de los principios constitucionales referentes a la organización, gobierno, administración, funcionamiento y control de los municipios y demás entidades locales. No obstante, este precepto está basado fundamentalmente en los principios constitucionales de 1961, pero aun así es aplicable a la actual Constitución de 1999, aunque será necesaria una reforma de esta ley para adaptarla a otros aspectos relacionados con el régimen municipal de la actual Constitución.

La LoRM, en el Artículo 36 del Título III, referido a las competencias municipales, establece que los municipios, para la gestión de sus intereses y en el ámbito de sus competencias, podrán promover toda clase de actividades y prestar cuantos servicios públicos contribuyan a satisfacer las necesidades y aspiraciones de la comunidad. De allí que en el ordinal 7 del mismo Artículo se establezca el servicio de transporte público urbano de pasajeros como parte de las competencias del municipio.

Asimismo, el hecho de que el Artículo 38 (literal d) establezca que se le imponen al municipio los servicios mínimos obligatorios, significa que el transporte público urbano es un servicio de prestación obligatoria para el municipio, mediante la gestión ya sea directa o indirecta (Gómez, 2001). Con base en el análisis legal que hace este autor, la competencia atribuida al municipio en materia de transporte público urbano de pasajeros, le corresponde a éste establecer el régimen de la prestación de ese servicio, lo que implica la regulación total del orden administrativo, incluyendo la fijación de tarifas.

Los municipios han asumido esa competencia de prestación tanto directa como indirectamente. La modalidad de gestión directa del servicio es viable en los municipios pequeños, mientras que en los municipios medianos y grandes se adopta alguna mo- 
dalidad de gestión indirecta, de las que establece el Artículo 41 de la LORM (Congreso de la República, 1989). Esa gestión indirecta puede ser mediante institutos autónomos municipales, mediante delegación; empresas, fundaciones, asociaciones civiles y otros organismos descentralizados del municipio, mediante contrato; u otros entes nacionales o estatales.

\section{Bases conceptuales para una propuesta de mejoramiento del servicio}

Las causas que han originado el deterioro del servicio de la Red Maestra evidencian a todas luces que la ruta que debe seguir una política pública local de intervención no sólo debe tomar en cuenta elementos de carácter técnico-administrativo, sino también, y para mejorar la calidad del servicio, la necesidad de desarrollar algunas condiciones mínimas que permitan romper con la inercia institucional, producto de la lógica política en que se encuentra envuelta la gestión del servicio debido a las múltiples presiones de los actores interesados.

En vista de ello, una bitácora teórica de análisis de la política puede permitir un proceso de reflexión que ayude a los diseñadores de un plan de intervención a reorientar las acciones a fin de obtener un mejoramiento del servicio que legitime la contención de cualquier intento de desviación en la administración del servicio con el que se quiera desvirtuar el verdadero objetivo con el que el servicio fue puesto en marcha en un principio: prestar un servicio de calidad al ciudadano. En este sentido, se considera que se debe tener claro lo que significa un servicio público local, y que se deben crear bases de sustentación del mismo a partir de la construcción de asociatividad, factor importante en toda aquella iniciativa que pretenda tener carácter de red.

\subsection{En búsqueda de una definición alternativa de Servicios Públicos Locales}

Lo costoso y hasta imposible que pasó a ser la tradicional estructura centralizada de Estado para gestionar las diversas demandas de los ciudadanos, dio pie a la consigna de que el small is beautiful, propia del localismo norteamericano (Meny y Thoenig, 1992). La delegación de tareas estatales al sector privado y al llamado "tercer sector", en el entendido de que pueden ser llevadas más eficientemente por actores y organizaciones pertene- 
cientes a esas esferas, se inserta en las políticas de concesión de funciones operativas al "sector público no estatal" (Cunill, 1997).

Debido a lo hegemónico que ha sido el paradigma de "reinvención del gobierno", en el cual se alega que es necesario delegar al sector privado y a la sociedad civil la ejecución de servicios operativos (Osborne y Gaebler, 1994: 55), los actuales conceptos sobre servicios públicos resaltan la importancia de la administración indirecta. En este sentido, Blanco (1999) afirma que el servicio público consiste en la satisfacción de una necesidad colectiva por parte de la administración pública, de manera regular y continua y en igualdad de condiciones para todos los usuarios, conforme al ordenamiento jurídico; la principal obligación para la administración es garantizar la prestación del servicio, y para el usuario, el pago de la tasa a la administración.

En la búsqueda de diluir el carácter populista del Estado, disfuncional al principio de competencia, los esfuerzos actuales se orientan a descargarlo de responsabilidades de interés público, las cuales representan para el sector privado una oportunidad de negocio dado que se sustentan sobre necesidades sociales secularizadas que deben ser satisfechas a todo trance. En el caso de los gobiernos locales, el diseño está planteado en términos de: $a$ ) autonomía en la gestión para la provisión de infraestructura y servicios; $b$ ) privatización y tercerización de tal prestación; $c$ ) impulso de una competencia administrada por las autoridades locales, y $d$ ) regulación y control de la provisión por parte de la ciudadanía.

La grave crisis fiscal ha obligado a asumir el criterio de recuperación de costos en la esfera de la administración de los programas públicos. Dicho criterio se ha expresado en la ejecución de tareas ligadas fundamentalmente al trinomio: privatización, descentralización y participación, obligando al individuo a lo que Gyford denomina "praxis de activación de roles", basada en la necesidad de "redefinir los papeles clásicos pasivos de contribuyente, receptor y votante en los nuevos de accionista, consumidor y ciudadano” (Gyford, 1991, citado por Brugé et al., 1994: 37).

El nuevo espacio público que surge de la reestructuración económica y social exige nuevas mentalidades y actitudes, orientadas de acuerdo con principios que aminoren las sobredimensionadas expectativas de la población y que promocionen valores como la participación, la autogestión, la eficiencia y la productividad. Con el emblema de "democratizar la democracia" se ha apelado a los poderes redentores de la demos como 
fórmula expedita para contrarrestar los efectos tanto de un aparato público insensible como de las imperfecciones del mercado.

Frente a ello es posible desarrollar una definición de los llamados Servicios Públicos Locales (SPL) que tenga en cuenta los costos pero que no elimine el carácter de subsidiariedad y hasta de gratuidad que debe estar presente en cualquiera de los servicios dirigidos a satisfacer necesidades básicas. En este sentido, creemos que los SPL son un actividad con alcance universal y extensivo de obligatoria prestación, de manera directa o indirecta, por parte del Estado en el ámbito municipal, y que tienen el propósito de satisfacer una necesidad de interés público; y el usuario recibe dicho servicio, bien sea por el pago de una tarifa determinada sobre la base de la estructura de costo y del subsidio estatal que recibe el servicio, o mediante un régimen gratuito, sustentado por la vía de los impuestos que recaba el municipio.

\subsection{La necesidad de generar capital social para lograr asociatividad}

La teoría del capital social tiene sus raíces en el llamado "nuevo institucionalismo", el cual reconoce a las instituciones "como un conjunto de pautas de actividad supraorganizativas mediante las cuales los seres humanos rigen su vida material en el espacio y en el tiempo, y como un conjunto de sistemas simbólicos de los que se sirven para categorizar esa actividad y dotarla de significado" (Friedland y Alford, 1993: 156).

El trabajo pionero sobre "capital social” fue desarrollado por Robert Putnam (1993) el estudio de los factores que incidieron en las diferencias de desarrollo entre la Italia del Norte y la Italia del Sur. Según este autor, "el capital social refiere a las características de la organización social, tales como la confianza, las normas y las redes de trabajo que pueden mejorar la eficiencia de la sociedad facilitando acciones coordinadas" (1993: 167).

El legado de una comunidad cívica desde los tiempos del Medioevo, con capacidad para autoorganizarse y actuar cooperativamente, se estableció en el tejido social como un esquema de valores y pautas de ordenación compartidas que mediaron decididamente en el desarrollo de las comunidades de la Italia del Norte. El principio fundamental que se deduce de la tesis de Putnam es que aquellas sociedades que cuenten con acervo cultural e institucional favorable tienen mayores posibilidades de desarrollarse política, económica y socialmente. 
La tesis de Putnam ha sido convalidada últimamente por Ronald Inglehart (1998), quien sostiene que la existencia de redes organizativas de carácter voluntario y la confianza societal son variables adicionales que han incidido en el desarrollo económico y la estabilidad de la democracia en muchas naciones. A partir de un impresionante estudio comparativo que toma como muestra a 43 países, este autor señala que la presencia de variables culturales como la motivación para el logro, valores posmaterialistas y factores de capital social como la pertenencia a asociaciones, son complementarios de las variables económicas a la hora de producir desarrollo.

Aunque Inglehart afirma en su trabajo que sus resultados no son muy representativos de los países latinoamericanos, los cuales presentan mas bien una condición media o nula de esos rasgos, otros autores como Bernardo Klisksberg (1999) han señalado la presencia en América Latina de ciertas experiencias exitosas de democratización y desarrollo económico local, en donde el capital social ha jugado un papel importante para el impulso de la participación.

El énfasis en la tradición y la experiencia organizativa de la comunidad como condicionante de la participación, tal como lo plantea la tesis del capital social, nos lleva nuevamente a retomar la mencionada idea del juego de herramientas como dispositivo para desplegar estrategias de acción. Es este sentido, conseguimos otro punto de encuentro entre las diversas posiciones que han tratado de explicar la acción colectiva, las cuales, cada una por su lado, observan grandes limitaciones para obtener un óptimo nivel comprensivo.

El capital social refiere a experiencias y tradiciones simbólicas de las que hacen uso los individuos para construir líneas de acción. Así, ese capital se comporta como un bagaje cultural al que se recurre dentro del conjunto de elementos simbólicos para emular y desarrollar prácticas y acciones colectivas que han tenido un efecto positivo en anteriores situaciones históricas en la vida de la comunidad.

\section{Consideraciones finales: hacia una Red Maestra de Líneas Cooperativas de Autobuses de Transporte Colectivo Urbano}

Considerándose como válidas las premisas teóricas anteriores, una propuesta que contribuya al mejoramiento de la Red Maestra de Transporte Urbano de Maracaibo puede iniciarse con una 
acción orientada a darle organicidad a un desarrollo de líneas cooperativas de autobuses basado en la experiencia organizativa que han tenido las cooperativas de carros por puestos. Una primera fase del proyecto sería la conformación de líneas cooperativas de transporte a partir de la reconversión de los propietarios de las unidades pequeñas de transporte en titulares de autobuses, utilizándose para ello los recursos que pueda proveer el Fontur, o también mediante el Fondo Intergubernamental para la Descentralización (Fides) y con los recursos otorgados al municipio según la Ley de Asignaciones Especiales (Laes), que manejan un porcentaje de financiamiento para aquellos grupos de la sociedad civil organizada.

Desde esa perspectiva se estaría generando un sentido de propiedad por parte de los miembros de las cooperativas sobre las unidades, lo cual representaría un incentivo para que las mismas gozaran de mantenimiento preventivo, institucionalizándose dicha acción como una rutina propia de la organización. Así, la democratización de la propiedad sería el mejor mecanismo para que la propia cooperativa se autorregule y controle la prestación del servicio, desarrollando su atractivo ante el usuario mediante un servicio eficiente y de calidad, haciéndose así competitivo frente a otras modalidades de transporte.

La generación de cooperativas de transporte para la gestión de la Red Maestra posibilitaría también un espacio para el desarrollo económico de los miembros que tendría un efecto multiplicador en el propio municipio. En vez que las operadoras de transporte fueran empresas privadas orientadas por el afán de lucro, la adjudicación de las operaciones a las cooperativas significaría una mejora en la calidad de vida de los miembros, ya que ellos mismos, como dueños y operadores de las unidades, recibirían las utilidades que derivaran de una actividad que generalmente ha presentado alto margen de rentabilidad cuando se maneja de manera adecuada.

Una segunda fase sería la integración de las líneas a un trazado que empalme, en puntos de alto acopio de pasajeros pero de bajo congestionamiento vehicular, las rutas ya asignadas y en las que ya lleva tiempo operando de manera independiente cada cooperativa de unidades. En ese momento es necesario involucrar al ciudadano a fin de que participe en la identificación de los puntos de enlace, ya que éste, según sus necesidades, conoce mejor cuáles pueden ser los sitios que resultan tener cierta centralidad como para convertirlos en espacio de encuentro. 
Por otro lado, es fundamental el compromiso del gobierno local en el desarrollo de un esquema de subsidio que permita abaratar los costos del servicio. Una posible fuente de financiamiento local se puede lograr con el mejoramiento de la recaudación del impuesto de patente de vehículo que pagan los contribuyentes propietarios de automóviles en el municipio. El hecho de que los ciudadanos que posean vehículo para su uso personal sustenten mediante el pago de un impuesto el servicio de transporte de aquellos que no poseen automóvil, es un ejemplo de equidad en la gestión de una ciudad.

Ahora bien, esto es apenas un pequeño bosquejo de lo que podría ser una propuesta para enfrentar el deterioro de la Red Maestra. De allí que falte mucho camino por recorrer en la confección detallada de las acciones, que deben asumir no sólo las autoridades locales sino también las propias cooperativas. Sin embargo, hay que dejar claro que en la ejecución de esas acciones debe mediar una serie de mecanismos de control y de rendición de cuentas sobre las responsabilidades y recursos; y para ello se deben abrir canales para la participación de los usuarios, cuestión que ha estado ausente en amplia medida. Pero esto, en todo caso, es una discusión que escapa a los objetivos de este trabajo.

\section{Bibliografía}

Asamblea Nacional Constituyente (1999), Constitución de la República Bolivariana de Venezuela, Gaceta Oficial, núm. 36.860, 30 de diciembre, Caracas.

Barzelay, Michael (1998), "La reforma de la administración pública: un enfoque de políticas (con referencia a los países de la OCDE)", Reforma y Democracia, Revista del Centro Latinoamericano de Administración para el Desarrollo, Caracas, 10:113-128.

Borja, Jordi (2002), “Gobiernos locales, políticas públicas y participación ciudadana”, Aportes, Revista de la Asociación de Administradores Gubernamentales, Argentina, año 9, 19: 57-65.

Brugué, Quin, M. Amorós y Ricard Gomà (1994), "La administración pública y sus clientes: ¿Moda organizativa u op- 
ción ideológica?”, Gestión y Análisis de Políticas Públicas, Madrid, 1: 33-46.

Congreso de la República de Venezuela (1989), Ley Orgánica de Régimen Municipal, Gaceta Oficial Extraordinaria, núm 4.109, 15 de junio, Caracas.

Crozier, Michel (1997), "La transición del paradigma burocrático a una cultura de gestión pública”, Reforma y Democracia, Revista del Centro Latinoamericano de Administración para el Desarrollo, Caracas, 7: 7-18.

Cunill, Nuria (1997), Repensando lo público a través de la sociedad, Editorial Nueva Sociedad-ClAD, Caracas.

(1999), “¿Mercantilización y neo-clientelismo o reconstrucción de la administración pública? Retos de las reformas de segunda generación”, Nueva Sociedad, Caracas, marzo-abril, 160: 101-117.

Dunleavy, Patrick y Christopher Hood (1995), "De la administración pública tradicional a la nueva gestión pública. Ensayo sobre la experiencia modernizadora de diversos países desarrollados”, Gestión y Análisis de Políticas Públicas, Madrid, 3: 105-114.

Figueroa, Oscar (2004), "Infraestructura, servicios públicos y expansión urbana en Santiago", en Santiago en la globalización ¿una nueva ciudad?, Ediciones Sur, Chile, pp. 243-272.

Friedland, Roger y Robert Alford (1993), "La sociedad regresa al primer plano: símbolos, prácticas y contradicciones institucionales”, Zona Abierta, Madrid, 63/64: 155-207.

Gomà, Ricard y Quim Brugué (1994), "Nuevos modelos de gestión y organización pública”, Autonomies, Universidad Autónoma de Barcelona, 18: 207-229.

Gómez, Oscar (2001), "Reforma del Estado y necesidad de cambio en la administración municipal venezolana”, Revista Ciencias de Gobierno, Instituto Zuliano de Estudios Políticos, Económicos y Sociales, Maracaibo, Venezuela, núm. 9. 
INE (Instituto Nacional de Estadística) (2005), Estadísticas oficiales, www.ine.gov.ve, 14 de octubre de 2005.

Inglehart, Ronald (1998), Modernización y posmodernización. El cambio cultural, económico y político en 43 sociedades, Centro de Investigaciones Sociológicas (CIS), Madrid.

Klisksberg, Bernardo (1999), "El rol del capital social y de la cultura en el proceso de desarrollo", Revista Venezolana de Gerencia, Universidad del Zulia, Maracaibo, Venezuela, año 4, 9: 11-50.

Meny, Ives y Jean-Claude Thoenig (1992), Las políticas públicas, Editorial Ariel, Barcelona.

North, Duoglass (1993), Instituciones, cambio institucional y desempeño económico, Fondo de Cultura Económica, México.

Osborne, Gabriel y Ted Gaebler (1994), La reinvención del gobierno, Ediciones Paidós, Buenos Aires.

Putnam, Robert (1993), Making Democracy Work: Civic Traditions in Modern Italy, Princeton University Press, Princeton, Nueva Jersey.

José Guillermo García Chourio es candidato a doctor por la Universidad Internacional de Andalucía (España) y por la Universidad Complutense de Madrid. Algunos de sus méritos académicos son: la obtención del primer lugar en la XxxIII Promoción de Sociólogos de la Universidad del Zulia; becario del Fonacit en el Programa de Fortalecimiento a la Investigación; beca completa de maestría otorgada por la Universidad Internacional de Andalucía; beca matrícula en el iv Programa de Maestría en Gerencia Pública de la Universidad del Zulia; beca completa de doctorado otorgada por la Universidad Internacional de Andalucía; beca de doctorado otorgada por la Agencia Española de Cooperación Internacional (AECI). Entre sus publicaciones se encuentran: "El papel de las identidades culturales en la rearticulación Estado-sociedad civil en América Latina”, Revista Venezolana de Ciencias Sociales, Universidad Nacional Experimental Rafael María Baralt, vol. 3, núm. 1, 1999; "Reforma de la administración de justicia en Venezuela", 
Revista de Ciencias Sociales, Universidad de Costa Rica, núm. 95, 2002; "Mas allá de la personalización de la política: desalineamiento electoral y realineamiento ideológico en Venezuela", Cuestiones Políticas, Universidad del Zulia, núm. 26, 2002; y "De la primera a la segunda generación de Reformas del Estado en América Latina: giro ideológico y cambio conceptual", Cuadernos de Economía, Universidad Nacional de Colombia, Bogotá, núm. 38, vol. XXII, 2003. 